\title{
Once weekly semaglutide for treatment of obesity
}

Nasser Mikhail, MD, MSc*, Vahid Mahabadi, MD

Endocrinology Division, Department of Medicine, Olive View-UCLA Medical Center, David-Geffen UCLA Medical School, CA, USA.

*Corresponding Author: Nasser Mikhail, Endocrinology Division, Department of Medicine, Olive View-UCLA Medical Center, DavidGeffen UCLA Medical School, CA, USA.

Received date: March 23, 2021; Accepted date: April 07, 2021; Published date: April 09, 2021

Citation: N Mikhail, V Mahabadi. (2021) once weekly semaglutide for treatment of obesity. Journal of Clinical and Laboratory Research. 2(3) DOI: $10.31579 / 2768-0487 / 015$

Copyright: (2021 Nasser Mikhail. This is an open-access article distributed under the terms of the Creative Commons Attribution License, which permits unrestricted use, distribution, and reproduction in any medium, provided the original author and source are credited.

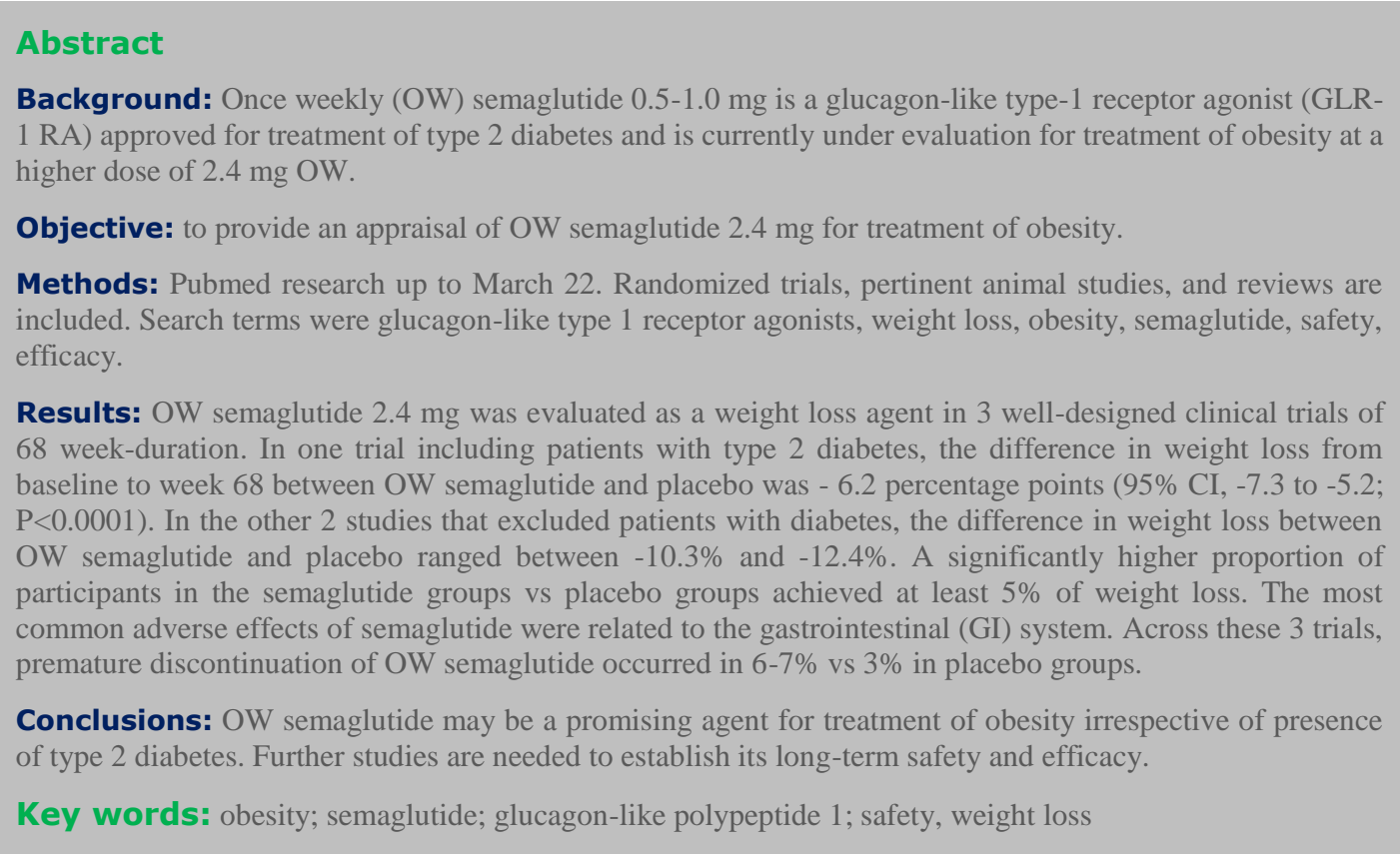

\section{Introduction}

GLP-1 RAs are approved for treatment of type 2 diabetes. The drug profile of these drugs is characterized by mild dose-related weight loss of approximately 2-6 kg [1]. Currently, liraglutide is the only GLP-1 RA approved for treatment of obesity in a dose higher than that approved for type 2 diabetes $(3 \mathrm{mg}$ daily for treatment of obesity as opposed to maximum dose of $1.8 \mathrm{mg} / \mathrm{d}$ in type 2 diabetes) [2]. Semaglutide is a longacting GLP-1 RA that can be administered once weekly in a dose of 0.5 $1.0 \mathrm{mg}$ for treatment of type 2 diabetes [3]. Since the magnitude of weight loss increases with the dose of GLP-1 RA, semaglutide is being evaluated as weight-loss agent at a higher weekly dose of $2.4 \mathrm{mg}$ [4-7]. The Semaglutide Treatment Effect in People with obesity (STEP) development program includes 5 phase 3 clinical trials (STEP 1 to 5) to evaluate efficacy and safety of OW semaglutide at this high dose of 2.4 $\mathrm{mg}$ for treatment of obesity in patients with and without diabetes [4]. Three trials of the STEP program have been published [5-7]. The purpose of this article is to provide an appraisal of OW semaglutide for treatment of obesity, with special emphasis on its efficacy and safety in this setting.

\section{Rationale for evaluation of semaglutide as treatment of obesity}

Data from trials of patients with type 2 diabetes suggest that $\mathrm{OW} 1.0 \mathrm{mg}$ semaglutide is superior to other GLP-1 RAs such OW exenatide ER $2 \mathrm{mg}$, OW dulaglutide $1.5 \mathrm{mg}$, and daily liraglutide $1.2 \mathrm{mg}$ in terms of reduction of weight and hemogolobin A1c (HbA1c) levels [1,8,9]. In addition, a meta-analysis of indirect comparison between semaglutide and the sodium-glucose transporter 2 inhibitor empagliflozin has shown that $\mathrm{OW}$ $1.0 \mathrm{mg}$ semaglutide was more effective than empagliflozin $25 \mathrm{mg} / \mathrm{d}$ in reducing weight (estimated treatment difference $-1.65 \mathrm{~kg}, 95 \% \mathrm{CI},-2.22$ to $-1.08, \mathrm{P}<0.0001$ ) [10]. Furthermore, OW $1.0 \mathrm{mg}$ semaglutide has been shown to decrease cardiovascular (CV) events in patients with type 2 diabetes who were at high cardiovascular risk [11]. Therefore, the STEP program was launched to evaluate the weight-loss effects of OW 
semaglutide $2.4 \mathrm{mg}$. This program consists of 5 trials, three of them were published [4-7].

\section{Mechanisms of weight loss by semaglutide}

In a randomized, double-blind trial including 72 obese subjects (mean weight $105.5 \mathrm{~kg}$ ), OW semaglutide was associated with $35 \%$ ad libitum energy intake compared with placebo after 20 weeks [12]. In addition, semaglutide significantly reduced hunger and food craving, and increased satiety and fullness versus placebo [12]. Importantly, gastric emptying, evaluated indirectly via paracetamol absorption, was not delayed in the semaglutide group after controlling for difference in weight between the semaglutide group and placebo group [12]. Animal studies have shown that the anorexigenic of semaglutide is mediated by GLP-1 receptors in the hypothalamus and hind brain $[13,14]$.

\section{STEP program}

STEP 1 to 3 trials are generally well-designed studies comparing OW 2.4 mg semaglutide with placebo in obese individuals (defined as BMI of $\geq$ $30 \mathrm{~kg} / \mathrm{m}^{2}$, over $\geq 27 \mathrm{~kg} / \mathrm{m}^{2}$ with $\geq 1$ weight-related coexisting condition e.g. hypertension, dyslipidemia, cardiovascular disease, or obstructive sleep apnea) for 68 week-duration [5-7]. Overview of STEP trials was summarized in table 1, Trials STEP 1 and 3 excluded patients with diabetes, whereas STEP 2 included exclusively patients with type 2 diabetes. In addition, STEP 2 included a third group of individuals randomized to the smaller anti-diabetic dose of semaglutide (OW $1.0 \mathrm{mg}$ ) [6]. In STEP 1 and 2, all participants receive lifestyle intervention defined as a $500 \mathrm{kcal}$ deficit relative to the estimated energy expenditure plus encouragement of increase physical activity, such as walking 150 minutes per week. In STEP 3 trial, all subjects received a low-calorie diet (1000$1200 \mathrm{kcal} / \mathrm{d}$ ) provided as meal replacement for the first 8 weeks. Subsequently, they were transitioned to a low-calorie diet (1200-1800 $\mathrm{kcal} / \mathrm{d}$ ) of conventional food. Moreover, they were prescribed $200 \mathrm{~min}$ of physical activity/week [7]. The coprimary endpoints of STEP 1 to 3 trials were the percentage change in body weight and weight reduction of at least $5 \%$ at week 68 compared with placebo [5-7].

\section{Weight loss in STEP 1-3 trials}

Weight loss started in the first few weeks after starting semaglutide and reached a nadir after 52-60 weeks [5-7]. In all STEP trials, semaglutide was significantly superior to placebo in the magnitude of weight loss. Thus, in STEP 1-3, semaglutide-treated subjects lost 6.2 to 10.3 percentage points greater than placebo after 68 weeks [5-7]. In STEP 2 that exclusively included patients with type 2 diabetes, the difference in weight loss vs placebo was relatively small (6.2 percentage point) [6]. The explanation of this finding is unclear but might be related to the coexistence of type 2 diabetes, relatively older patient population (mean age 55 in STEP 2 versus 46 year-old in STEP 1 and 3), or the lower baseline body weight (99.8 kg in STEP 2 versus approximately $105.5 \mathrm{~kg}$ in STEP 1 and 3). Across the STEP 1-3 trials, percentage of subjects who achieved $\geq 5 \%$ weight loss at 68 weeks was significantly greater with semaglutide than with placebo, $69-86 \%$ and $28-48 \%$, respectively (Table 1) [5-7]. A subgroup analysis $(n=140)$ in STEP 1 trial using dual-energy $\mathrm{x}$ ray absorptiometry (DXA) has shown that semaglutide administration was associated with reduction in total fat and regional visceral fat mass and to a lesser extent reduction in lean body mass [5].

\section{Glycemic effects of OW semaglutide in STEP trials}

In STEP 2 trial, mean $\mathrm{HbA} 1 \mathrm{c}$ reductions were $-1.6 \%,-1.5 \%$, and $-0.4 \%$ in the OW semaglutide $2.4 \mathrm{mg}$, OW semaglutide $1.0 \mathrm{mg}$, and placebo groups, respectively [6]. HbA1c levels were also reduced by approximately 0.2 to 0.3 percentage points in patients without diabetes in STEP 1 and 3 trials [5, 7]. Moreover, in STEP 1, 84.1\% of participants who had prediabetes at baseline reverted to normoglycemia at 68 weeks. Corresponding proportion was $47.8 \%$ in the placebo group [5].

\section{Effects of OW semaglutide on cardiovascular risk factors in STEP trials}

Significant reduction in systolic blood pressure (SBP) was recorded in subjects randomized to semaglutide in STEP1-3 trials, approximately 4-5 $\mathrm{mmHg}$ lower than in individuals randomized to placebo [5-7]. Likewise, a significant reduction in DBP of approximately $2 \mathrm{mmHg}$ was observed in STEP 1 and 3 trials $[5,7]$. Changes in lipid panel were generally mild. Thus, reduction in plasma triglycerides of $14-17 \%$ compared to placebo was the most consistent change in lipid panel. Minor reductions in concentrations of low-density lipoprotein-cholesterol (LDL-C) (by $\leq 7 \%$ vs placebo) and increase in high-density lipoprotein-cholesterol (HDL-C) levels (by <5\% vs placebo) were also observed. In addition, there was significant reduction in the inflammatory marker C-reactive protein (CRP) levels in semaglutide-treated subjects vs placebo [5-7]. The above favorable changes in blood pressure, lipids and CRP are likely attributed to weight loss per se and are unlikely to be direct effects of semaglutide.

\section{Effects of semaglutide on physical functioning and quality of life}

Greater improvements in physical functioning scores and quality of life were seen with semaglutide than with placebo $[5,6]$.

\section{Safety of once weekly semaglutide $2.4 \mathbf{~ m g}$}

Overall, OW semaglutide $2.4 \mathrm{mg}$ was fairly tolerated. This conclusion is based on the proportions of subjects who discontinued trial drug prematurely due to adverse effects, $5.9-7 \%$ in semaglutide groups versus 2.9-3.5\% in the placebo groups across STEP 1 to 3 trials [5-7]. It was somewhat reassuring that over 68 weeks of semaglutide therapy, no signals of increased incidence of cancer or pancreatitis were observed.

\section{Gastrointestinal adverse effects}

In STEP 1-3, GI adverse effects were the most common events reported by approximately $63-83 \%$ and $34-63 \%$ in subjects randomized to OW semaglutide and placebo, respectively [5-7]. Among the GI adverse effects, nausea was the most frequent, followed by diarrhea, vomiting and constipation. The frequency of GI symptoms increased early in the first few weeks during drug titration. They were generally described as mild to moderate and transient. However, they were severe in a minority of patients. In fact GI adverse effects were the most frequent cause of premature drug withdrawal. Thus, drug discontinuation due to GI adverse effects occurred in $3.4-4.5 \%$ and $0-1.0 \%$ in patients randomized to OW semaglutide and placebo, respectively [5-7].

Previous trials in type 2 diabetes using OW $1.0 \mathrm{mg}$ semaglutide have shown that GI adverse effects tend to be more common with semaglutide compared with other GLP-1 agonits [15]. Meanwhile, post-hoc analysis by Lingway et al [15] suggest that GI adverse effects contribute minimally (less than $0.1 \mathrm{~kg}$ ) to the superior weight loss effects of semaglutide vs other GLP-1RA agonists. Incidence of cholelithiasis and cholecystitis was slightly higher in STEP 1 and 3 trials $(2.5-2.6 \%$ with semaglutide versus $0-1.2 \%$ with placebo) $[5,7]$. These events are attributed in part due to weight loss, but other mechanisms could be involved such as inhibition of gallbladder contraction and biliary motility [16].

\section{Diabetic retinal disorders}


Worsening diabetic retinopathy was observed previously in association with use of OW semaglutide 0.5-1.0 mg [11]. In STEP 2, there was a trend towards increase in incidence of retinal disorder events in the 2 semaglutide arms compared with the placebo arm [6]. Thus, these events occurred in $6.9 \%, 6.2 \%$, and $4.2 \%$ in patients randomized to $\mathrm{OW}$ semaglutide $2.4 \mathrm{mg}$, OW semaglutiude $1.0 \mathrm{mg}$, and placebo, respectively (statistical significance level was not reported). No doubt, this safety issue requires further studies.

\section{Hypoglycemia}

In STEP 2 trial, severe or blood-glucose confirmed symptomatic hypoglycemia occurred in $5.7 \%$ and $3.0 \%$ of patients receiving OW semaglutide $2.4 \mathrm{mg}$ and placebo, respectively [6]. Interestingly, in patients without diabetes, frequency of hypoglycemia with OW semaglutide was low (0.5-0.6\%) and similar to placebo (0-0.8\%) [5-7].

\section{Advantages and limitations of semaglutide}

OW semaglutide $2.4 \mathrm{mg}$ offers several advantages as potential drug for treatment of obesity. First, its short-term efficacy and safety are supported by 3 well-designed randomized trials [5-7]. Second, being an anti-diabetic drug, it may be particularly useful in obesity-related type 2 diabetes by causing reduction of both weight and hyperglycemia [6]. Third, the OW administration of semaglutide may enhance prolonged drug adherence. Meanwhile, OW semaglutide has several limitations. First, the common occurrence of GI adverse effects represents one of the most important limitations of OW semaglutide. Second, the duration of therapy in clinical trials was short (68 weeks) [5-7]. Thus, the durability of its weight loss effect is still unknown. In fact, in the full-analysis set of STEP1-3 trials, the maximum weight loss was achieved after 52 weeks followed by a slight rebound [5-7]. Therefore, it is unclear to what extent weight regain may occur after stopping the drug. Indeed, in the STEP1-3 trials, followup extended for 7 weeks after trial end to evaluate short-term safety. Unfortunately, the investigators did not report any weight data at this time period after the end of drug admnistration. Nevertheless, the ongoing STEP 4 will address this issue as it includes a group of subjects who switch from semaglutide to placebo [4]. Third, long-term safety of OW semaglutide for several years is unknown. The ongoing STEP 5 may in part clarify this problem as it extends over a 2-year period [4]. Fourth, drug cost is virtually another limitation. Advantages and limitations of OW semaglutide are summarized in table 1.

\begin{tabular}{|c|c|c|c|}
\hline Trial & STEP 1 [5] & STEP 2 [6] & STEP 3 [7] \\
\hline Design & $\begin{array}{l}\text { Randomized, double-blind, } \\
\text { PL-controlled, } 2 \text { groups, } \\
\text { 2:1 ratio }\end{array}$ & $\begin{array}{l}\text { Randomized, double blind, } \\
\text { double-dummy, PL- } \\
\text { controlled, } 3 \text { equal groups }\end{array}$ & $\begin{array}{l}\text { Randomized, double-blind, } \\
\text { PL-controlled, } 2 \text { groups, } \\
\text { 2:1 ratio }\end{array}$ \\
\hline Patients & $\begin{array}{l}\mathrm{N}=1961,74.1 \% \mathrm{~W} \text {, mean } \\
\text { age } 46, \text { mean weight } 105 \\
\mathrm{~kg} \text {, mean BMI } 37.9 \mathrm{~kg} / \mathrm{m}^{2}\end{array}$ & $\begin{array}{l}\mathrm{N}=1210 \text { with type } 2 \\
\text { diabetes, } 50.9 \% \mathrm{~W} \text {, mean } \\
\text { age } 55 \text {, mean weight } 99.8 \\
\mathrm{~kg} \text {, mean BMI } 35.7 \mathrm{~kg} / \mathrm{m}^{2} \text {, } \\
\text { mean HbA1c } 8.1 \%\end{array}$ & $\begin{array}{l}\mathrm{N}=611,81.0 \% \mathrm{~W}, \text { mean } \\
\text { age } 46 \text {, mean weight } 105.8 \\
\mathrm{~kg} \text {, mean BMI } 38.0 \mathrm{~kg} / \mathrm{m}^{2}\end{array}$ \\
\hline Intervention & $\begin{array}{l}\text { S } 2.4 \text { mg OW }(n=1306) \text { vs } \\
\text { PL } \quad(n=655)+\text { lifestyle } \\
\text { intervention in all patients }\end{array}$ & $\begin{array}{l}\text { S } 2.4 \mathrm{mg} \text { OW }(\mathrm{n}=404), \mathrm{S} \\
1.0 \mathrm{mg} \text { OW }(\mathrm{n}=403), \mathrm{PL} \\
(\mathrm{n}=403)+\quad \text { lifestyle } \\
\text { intervention in all patients }\end{array}$ & $\begin{array}{l}\mathrm{S} 2.4 \mathrm{mg} \text { WO }(\mathrm{n}=407) \mathrm{PL} \\
(\mathrm{n}=204)+\text { intensive } \\
\text { behavioral therapy }+ \text { low- } \\
\text { calorie in the first } 8 \text { weeks } \\
\text { in all patients }\end{array}$ \\
\hline $\begin{array}{l}\text { Percentage mean weight } \\
\text { loss from baseline }\end{array}$ & $\begin{array}{l}\mathrm{S}-14.9 \% \text { vs PL }-2.4 \% \\
\text { difference }-12.4 \%(95 \% \mathrm{CI} \text {, } \\
-13.4 \text { to }-11.5 \%, \mathrm{P}<0.001)\end{array}$ & $\begin{array}{l}\text { S } 2.4 \mathrm{mg}-9.6 \% \text { vs PL - } \\
3.4 \% \text {, difference }-6.2 \% \\
(95 \% \text { CI }-7.3 \text { to }-5.2, \mathrm{P} \\
<0.0001) . \\
\text { S } 1.0 \mathrm{mg}-7.0 \%\end{array}$ & $\begin{array}{l}\text { S } 2.4 \mathrm{mg}-16.0 \% \text { vs PL - } \\
5.7 \% \text {, difference }-10.3 \% \\
(95 \% \mathrm{CI},-12.0 \text { to }-8.6, \mathrm{P} \\
<0.0001)\end{array}$ \\
\hline $\begin{array}{l}\text { Percentage of patients } \\
\text { with }>5 \% \text { weight loss }\end{array}$ & $\begin{array}{l}\text { S } 86.4 \% \text { vs PL } 31.5 \% \text {, (P } \\
<0.001)\end{array}$ & $\begin{array}{l}\mathrm{S} 2.4 \mathrm{mg} 68.8 \% \text { vs } \mathrm{PL} \\
28.5 \% \text {, OR } 4.88(95 \% \mathrm{CI} \text {, } \\
3.5 \text { to } 6.64, \mathrm{P}<0.0001) \\
\text { S } 1 \mathrm{mg} 57.1 \%\end{array}$ & $\begin{array}{l}\mathrm{S} 2.4 \mathrm{mg} 86.6 \% \text { vs PL } \\
747.6 \%(\mathrm{P}<0.0001)\end{array}$ \\
\hline $\begin{array}{l}\text { Percentage of patients } \\
\text { with }>10 \% \text { weight loss }\end{array}$ & $\begin{array}{l}\mathrm{S} 69.1 \% \text { vs } \\
\mathrm{P}<0.001\end{array}$ & $\begin{array}{lrrrr}\mathrm{S} 2.4 & \mathrm{mg} & 45.6 \% & \text { vs } & \mathrm{PL} \\
8.2 \% . & \mathrm{P} & \text { value } & \text { not } \\
\text { mentioned. } & & & \\
\end{array}$ & $\begin{array}{l}\mathrm{S} 2.4 \mathrm{mg} 75.3 \% \text { vs } \mathrm{PL} \\
27.0 \%(\mathrm{P}<0.001)\end{array}$ \\
\hline $\begin{array}{l}\text { Discontinuation of trial } \\
\text { drug due to adverse } \\
\text { effects }\end{array}$ & S $2.4 \mathrm{mg} 7.0 \%$ vs PL $3.1 \%$ & $\begin{array}{l}\text { S 2.4: } 6.2 \%, \text { S } 1.05 .0 \%, \text { PL } \\
3.5 \%\end{array}$ & S $2.45 .9 \%$ vs PL $2.9 \%$ \\
\hline Serious adverse effects & S $2.49 .8 \%$ vs PL $6.4 \%$ & $\begin{array}{l}\text { S } 2.49 .9 \%, \text { S1 } 7.7 \%, \text { PL } \\
9.2 \%\end{array}$ & S $2.45 .7 \%$ vs PL $0 \%$ \\
\hline
\end{tabular}

\section{Table 1: Overview of STEP trials}

\section{Abbreviations}

W: women, BMI: body mass index, S: semaglutide, OW: once weekly, PL: placebo, HbA1c: hemoglobin A1c, CI, confidence intervals

\section{Conclusions and current directions}

Overall, once weekly semaglutide $2.4 \mathrm{mg}$ added to healthy life-style changes represents a promising new drug for treatment of obesity given 
its acceptable short-term efficacy and safety. Longer term trials are underway to evaluate the durability of its weight loss action and long-term safety. The incidence of cancer and possible worsening of diabetic retinopathy should be carefully examined during the studies underway. In addition, the impact of OW semaglutide on CV events and mortality is unknown, In this regard, the SELECT study is an ongoing, double-blind placebo-controlled trial specifically designed to examine the effect of $\mathrm{OW}$ semaglutide $2.4 \mathrm{mg}$ on $\mathrm{CV}$ outcomes in overweight and obese persons with established CV disease who do not have diabetes. This SELECT study started in November 2018 and is expected to recruit 17,500 participants, and last for approximately a total of 59 months. Data derived from this large trial should further clarify the safety profile of OW semaglutide.

\section{Conflict of interest}

The authors do not have any conflict of interest.

\section{Advantages}

Acceptable weight loss efficacy

Amelioration of $\mathrm{HbA} 1 \mathrm{c}$ levels in patients with type 2 diabetes

Easy administration once weekly

\section{Limitations}

Common occurrence of gastrointestinal adverse effects

Lack of long-term efficacy and safety data

Expected high cost

\section{References}

1. Pratley RE, Aroda VR, Lingvay I, Lüdemann J, Andreassen C, et al (2018) for SUSTAIN 7 investigators. Semaglutide versus dulaglutide once weekly in patients with type 2 diabetes (SUSTAIN 7): a randomised, open-label, phase $3 \mathrm{~b}$ trial. Lancet Diabetes Endocrinol.6(4):275-286

2. Saxenda (Liraglutide). (2014) Prescribing information. Novo Nordisk A/S DK-2880 Bagsvaerd, Denmark.

3. Ozympic (semaglutide).( 2017) Prescribing information. Novo Nordisk A/S DK-2880 Bagsvaerd, Denmark.

4. Kushner RF, Calanna S, Davies M, Dicker D, Garvey WT, et al. (2020) Semaglutide $2.4 \mathrm{mg}$ for the Treatment of Obesity: Key Elements of the STEP Trials 1 to 5. Obesity (Silver Spring). 28(6):1050-1061.

5. Wilding JPH, Batterham RL, Calanna S, Davies M, Van et al (2021) for the STEP 1 Study Group. Once-Weekly Semaglutide in Adults with Overweight or Obesity. N Engl J Med. 384(11):989.

6. Davies M, Færch L, Jeppesen OK, Pakseresht A, Pedersen SD, et al (2021) for the STEP 2 Study Group. Semaglutide $2.4 \mathrm{mg}$ once a week in adults with overweight or obesity, and type 2 diabetes (STEP 2): a randomised, double-blind, doubledummy, placebo-controlled, phase 3 trial. Lancet. 397(10278):971-984.
7. Wadden TA, Bailey TS, Billings LK, Davies M, Frias JP, et al (2021) for the STEP 3 Investigators. Effect of Subcutaneous Semaglutide vs Placebo as an Adjunct to Intensive Behavioral Therapy on Body Weight in Adults with Overweight or Obesity: The STEP 3 Randomized Clinical Trial. JAMA. e211831.

8. Ahmann AJ, Capehorn M, Charpentier G, Dotta F, Henkel E, et al. (2018) Efficacy and Safety of Once-Weekly Semaglutide Versus Exenatide ER in Subjects with Type 2 Diabetes (SUSTAIN 3): A 56-Week, Open-Label, Randomized Clinical Trial. Diabetes Care. 41(2):258-266.

9. Capehorn MS, Catarig AM, Furberg JK, Janez A, Price HC et al. (2020) Efficacy and safety of once-weekly semaglutide 1.0 $\mathrm{mg}$ vs once-daily liraglutide $1.2 \mathrm{mg}$ as add-on to $1-3$ oral antidiabetic drugs in subjects with type 2 diabetes (SUSTAIN 10). Diabetes Metab. 46(2):100-109.

10. Lingvay I, Capehorn MS, Catarig AM, Johansen P, Lawson J, Sandberg A, Shaw R, Paine A. (2020) Efficacy of OnceWeekly Semaglutide vs Empagliflozin Added to Metformin in Type 2 Diabetes: Patient-Level Meta-analysis. J Clin Endocrinol Metab. 105(12):e4593-604.

11. Marso SP, Bain SC, Consoli A, Eliaschewitz FG, Jódar E et al (2016) for the SUSTAIN-6 Investigators. Semaglutide and Cardiovascular Outcomes in Patients with Type 2 Diabetes. N Engl J Med. 375(19):1834-1844.

12. Friedrichsen $\mathrm{M}$, Breitschaft A, Tadayon S, Wizert A, Skovgaard D. (2021) The effect of semaglutide $2.4 \mathrm{mg}$ once weekly on energy intake, appetite, control of eating, and gastric emptying in adults with obesity. Diabetes Obes Metab. 23(3):754-762.

13. Gabery S, Salinas CG, Paulsen SJ, Ahnfelt-Rønne J, Alanentalo $\mathrm{T}$, et al. (2020) Semaglutide lowers body weight in rodents via distributed neural pathways. JCI Insight. 5(6):e133429.

14. Drucker DJ. (2018) Mechanisms of Action and Therapeutic Application of Glucagon-like Peptide-1. Cell Metab. 27(4):740-756.

15. Lingvay I, Hansen T, Macura S, Marre M, Nauck MA, et al. (2020) Superior weight loss with once-weekly semaglutide versus other glucagon-like peptide-1 receptor agonists is independent of gastrointestinal adverse events. BMJ Open Diabetes Res Care. 8(2):e001706.

16. Pizzimenti V, Giandalia A, Cucinotta D, Russo GT, Smits M et al. (2016) Incretin-based therapy and acute cholecystitis: a review of case reports and EudraVigilance spontaneous adverse drug reaction reporting database. J Clin Pharm Ther. 41(2):1168.

17. Ryan DH, Lingvay I, Colhoun HM, Deanfield J, Emerson SS, (2020) Semaglutide Effects on Cardiovascular Outcomes in People With Overweight or Obesity (SELECT) rationale and design. Am Heart J.229:61-69. 